\title{
The Sintering Behaviour and Mechanical Properties of Hydroxyapatite - Based Composites for Bone Tissue Regeneration
}

\author{
CAMELIA TECU ${ }^{1}$, IULIAN ANTONIAC ${ }^{1}$, GULTEKIN GOLLER², BARIS YAVAS ${ }^{2}$, DAN GHEORGHE ${ }^{1 *}$, AURORA ANTONIAC ${ }^{1 *}$, \\ ION CIUCA ${ }^{1}$, AUGUSTIN SEMENESCUㄹ, ANCA DANIELA RAICIU³, IOAN CRISTESCU ${ }^{4}$ \\ ${ }^{1}$ University Politehnica of Bucharest, 313 Splaiul Independentei Str., 060042, Bucharest, Romania \\ ${ }^{2}$ Faculty of Chemical and Metallurgical Engineering, Istanbul Technical University, Resitpasa District, ITU Ayazaga Campus, \\ 34467, Istanbul, Turkey \\ 3Titu Maiorescu University, Faculty Pharmacy, Dept. Pharmacognosy Phytochem Phytoterapy, 16 Gh. Sincai Str., 040316, Bucharest, \\ Romania \\ ${ }^{4}$ Carol Davila University of Medicine and Farmacy, 37 Dionisie Lupu Str., 030167, Bucharest, Romania
}

\begin{abstract}
The developement and regeneration of healthy bone tissue is a complex process that includes the interaction of different cell types and requires a set of coordinated processes. The loss of bone tissue may occur due to various reasons: surgical removal, bone trauma (i.e., fractures) or systemic bone loss (i.e., osteoporosis). When the natural bone tissue is destroyed, the regeneration capacity of the bone is not always satisfactory. The result consists therefore in many functional and structural aberrations. In order to improve and accelerate the healing process, bone substitutes have been developed. Hydroxyapatite has been widely used in bone applications due to its excellent biocompatibility, osteoconductivity and bioactivity [1,2]. The objective of this research is to obtain a new composite biomaterial that can be used as bone substitute. In this study, bovine hydroxyapatite obtained from freshly calcined bovine femur was used. The objective of this research is to obtain a new composite biomaterial that can be used as bone substitute. The experimental composite samples were obtained using bovine hydroxyapatite as matrix and tricalcium phosphate, respectively, magnesium oxide as reinforcement materials. The synthesis process of these new biomaterial composites, the effect of chemical composition, surface structure, chemical and phase composition as well as mechanical features have been investigated.
\end{abstract}

Keywords: bone regeneration, composites, bovine hydroxyapatite, magnesium;

Bone defects have different origins (e.g. trauma, infection, etc.) [3-5] and in general, for repairing them, traditional methods such as autografts, allografts, and xenografts are used $[6,7]$. Even though autologous bone graft has many reasons to be considered the gold standard technique for bone filling defects, the technique has many limitations as well. Complications such as infection and chronic pain as well as limited self healing capacity of bone requires in general external intervention to improve bone regeneration [8]. A vast range of composite materials $[9,10]$ has been successfully used in bone applications, of all them, hydroxyapatite based bioceramics presenting a particular interest due to their high compatibility with the bone. The proper bone substituent has to mimick the structural features of the natural bone and thus, needs to have adequate mechanical properties and support the osteo-regeneration process. Due to its close similarity with the natural bone, hydroxyapatite has gained the attention of researchers [11]. Hydroxyapatite (HA) with the specific chemical formula $\mathrm{Ca}_{1}\left(\mathrm{PO}_{4}\right)(\mathrm{OH})$, can be synthesized through different methods, the most important being hydrolysis, chemical coprecipitation, hydrothermal synthesis and sol-gel process. An alternative method is the extraction from biological resources (e.g. bovine bones, marine shells, fish bones, eggshells, corals, etc.). Coming in both natural and synthetic forms, hydroxyapatite is one of the most popular calcium phosphate ceramics [12,13].

$\beta$-tricalcium phosphate ( $\beta$-TCP) with the chemical formula $\beta-\mathrm{Ca}_{3}\left(\mathrm{PO}_{2}\right)_{2}$ has been largely used as synthetic bone in orthopedics and dentisty applications. $\beta$-TCP bioceramics are biocompatible, bioresorbable and have similar properties to the mineral phase of bone. More than that, it has the potential to function as a source of calcium and phosphorus ions for tissue during the degradation process, which stimulates osteoblast function and promotes bone formation [14]. $\beta$-TCP is gradually resorbed by dissolution and fragmentation over a period of 6 to 18 months. Unfortunately, $\hat{a}-\mathrm{TCP}$ replacement by the bone is not satisfactory since there will be always a lower regenerated bone volume than the reabsorbed $\beta$-TCP volume $[15,16]$. For this reason, $\beta-$ TCP is clinically used as a complement to other bone graft substitutes with a lower resorption rate, being mostly used in association with hydroxyapatite. The association of $\beta$-TCP and HA offers better mechanical properties than $\beta$-TCP alone and enables $a$ a better bone ingrowth rate than using $\mathrm{HA}$ alone [17].

Because of the poor mechanical properties, hydroxyapatite is used in composites along with oxidic ceramics in order to obtain superior mechanical strength. Magnesium is an esential element that plays a signifacnt role in bone metabolism and promotes osteogenic activity. Magnesium oxide (MgO) represents an inorganic ceramic material of great importance [18]. The presence of magnesium in living calcified tissues (approximately 0.5\% in bone tissue or tooth enamel and more than $1 \%$ in dentin) suggests that this element can improve biocompatibility when used in combination with $\beta$-TCP [19-21]. Given the former considerations, magnesium oxide was chosen as a second filler besides $\beta$-TCP for HA based composites. The aim of the present work is to study the effects of the 


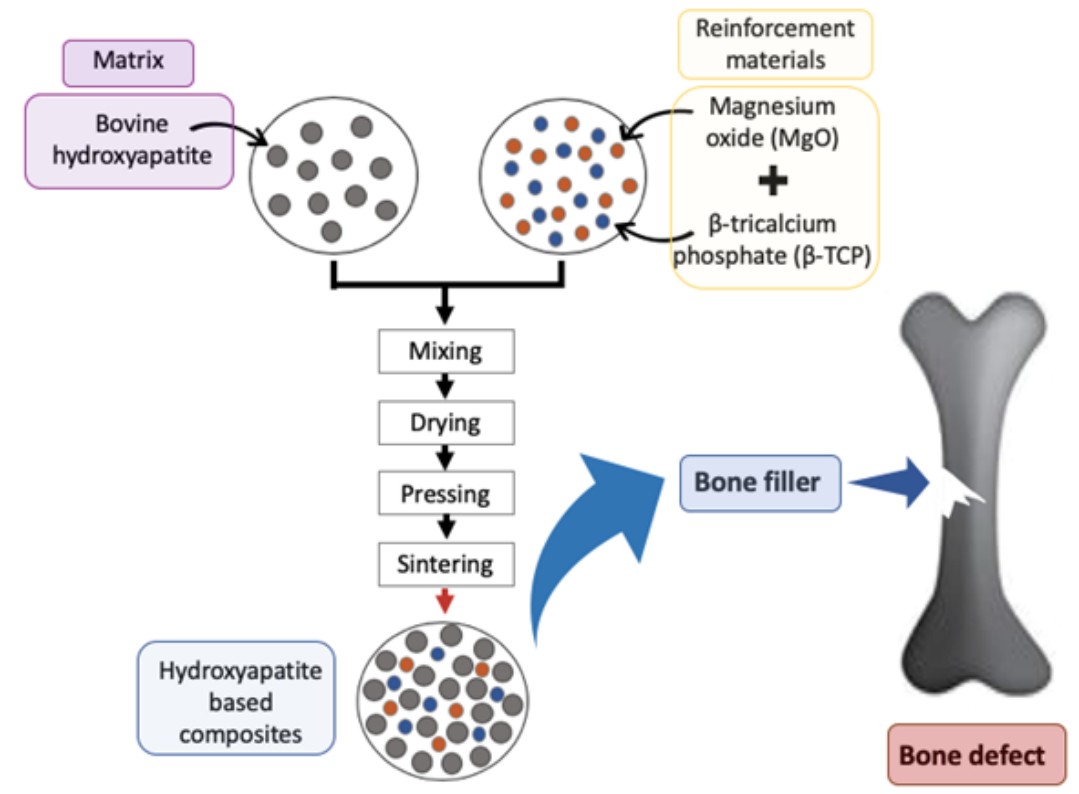

Fig. 1. Experimental process of obtaining bovine hydroxyapatite based composites

addition of different amounts of magnesium oxide and $\beta$ TCP, as well as sintering temperatures of the experimental hydroxyapatite composites.

\section{Experimental part}

\section{Materials and methods}

Bovine hydroxyapatite powder was obtained from freshly calcined bovine femur. The femoral head of the fresh bone was removed and the bone resulting from the femoral head cut was deproteinized with $\mathrm{NaOH}$ and, after washing, calcined at $850^{\circ} \mathrm{C}$ for $4 \mathrm{~h}$ in air. The powder obtained was subjected to a ball milling process (BM-0902). A mixture of hydroxyapatite powder, high purity alcohol (MERCK quality) and zirconia balls is prepared. Added elements respect the 1:3 ratio (HA : zirconia). Before being introduced into the mixture, the balls made of zirconia are washed with less pure alcohol. The mixture is placed in a milling machine specific container. The container will be attached to rotating cylinders that will rotate for $24 \mathrm{~h}$ at a speed of $200 \mathrm{rpm}$ (rotations per minute). After $24 \mathrm{~h}$, zirconium balls are removed so that only a mixture of powder and alcohol remains. The alcohol was evaporated using AREX - Heating Magnetic Stirrer set at 50 and 250 rpm (rotations per minute). To make sure the powder is completely dry, the container was placed in an incubator. After evaporation of the alcohol through the two processes, the ground powder was ready for use. Before using the hydroxyapatite powder to obtain composite materials, the particle size was measured and characterized by X-ray diffraction and scanning electron microscopy. The particle size was examined using laser technology with Particle size analyzer (Master Sizer 2000, Malvern Instrument). Following the analyzes, the mean particle size was found to be $3.022 \mu \mathrm{m}$. Also, small amounts of $0.8 \mu \mathrm{m}$ fine particles

Table 1

THE COMPOSITION OF EXPERIMENTAL COMPOSITES SAMPLES

\begin{tabular}{|c|c|c|c|}
\hline Sample code & A & B & C \\
\hline Bovine HA(\%wt) & 70 & 70 & 70 \\
\hline B-TCP(\%wt) & 10 & 15 & 20 \\
\hline MgO (\%wt) & 20 & 15 & 10 \\
\hline
\end{tabular}

were identified. The beta tricalcium-phosphate powder was purchased from SIGMA - ALDRICH. Magnesium oxide was purchased from Merck (Darmstadt, Germany), coded under the name of light, extra pure magnesium oxide; $\mathrm{Ph}$ Eur, BP, E 530, with a molecular weight of $40.3 \mathrm{~g} / \mathrm{mol}$. The developed composite biomaterials contain bovine hydroxyapatite (BHA) mixed with different percentages of fillers, respectively: beta tricalcium-phosphate and magnesium oxide (Table 1).

\section{Results and discussions}

\section{Fourier-Transform Infrared Spectroscopy}

Fourier Transform Infrared Spectrometry (FTIR) is one of the methods that monitors variations in structural groups and vibration bands providing information on the structure of calcium phosphates (HA and $\beta$-TCP) synthesized as bone substitute materials. The spectra recorded on the bovine source hydroxyapatite composites sintered at 1000 ${ }^{\circ} \mathrm{C}, 1100$ and $1200{ }^{\circ} \mathrm{C}$ are shown in Figure 2.

\section{$X$-Ray Diffraction}

$X$-ray diffraction is a primary and rapid analytical technique used to identify phases in a crystalline material and can provide information about unit cell sizes. It is a method of both qualitative and quantitative non-destructive analysis, which can provide information on the structural and chemical aspects in detail of a wide range of inorganic or organic materials. In this experimental study, a $30 \mathrm{kV}, 15$ mA Rigaku MiniFlex diffractometer was used to identify the structure of the crystalline compound, index the diffraction peaks and determine the network constants. Since hydroxyapatite decomposes at high temperatures, the intensity of hydroxyapatite peaks decreases with temperature rise.

\section{Scanning Electron Microscopy}

The scanning electron microscope uses a high-energy focused electron beam to generate a variety of signals on the solid surface of the sample. The signal generated by the interactions between electrons and sample provides information about the sample, including outer morphology (texture), chemical composition, crystalline structure and orientation of the materials from which the sample is composed. It is noted that the microstructure evolves with the increase of the sintered temperature of the bovine hydroxyapatite based composites. Thus, in this case a general tendency of poor sintering at low temperatures 

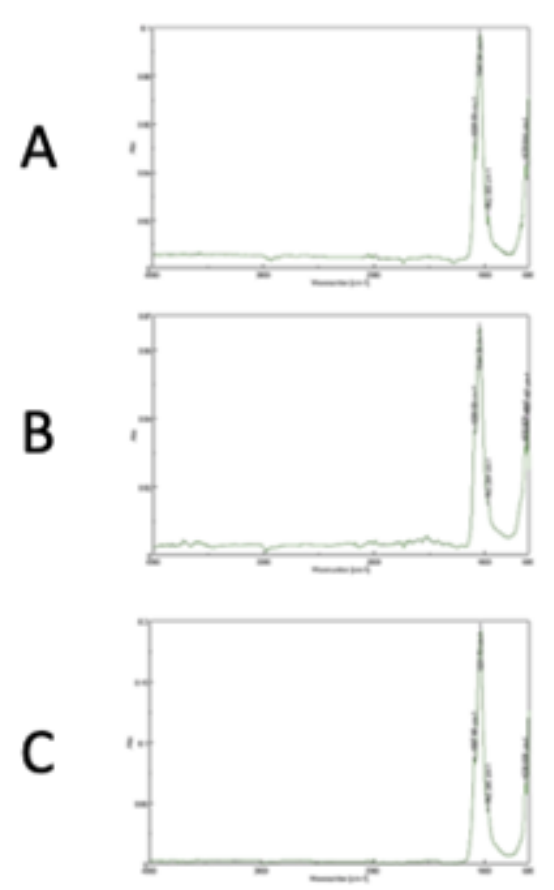

(a)
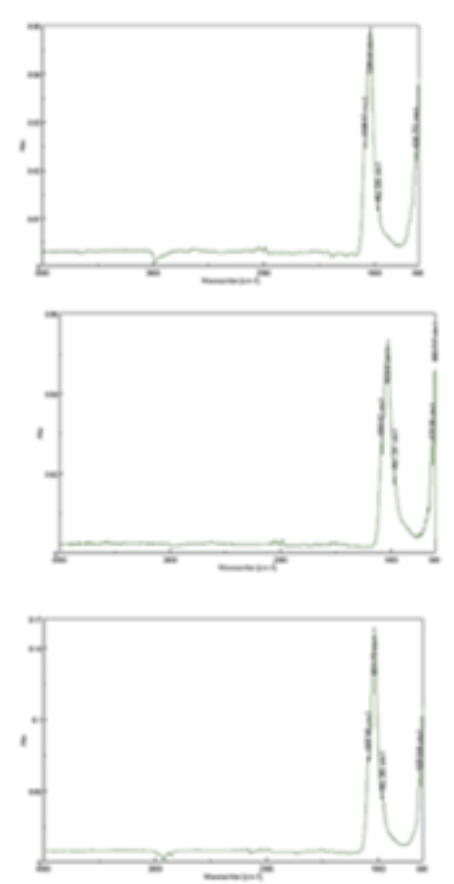

(b)
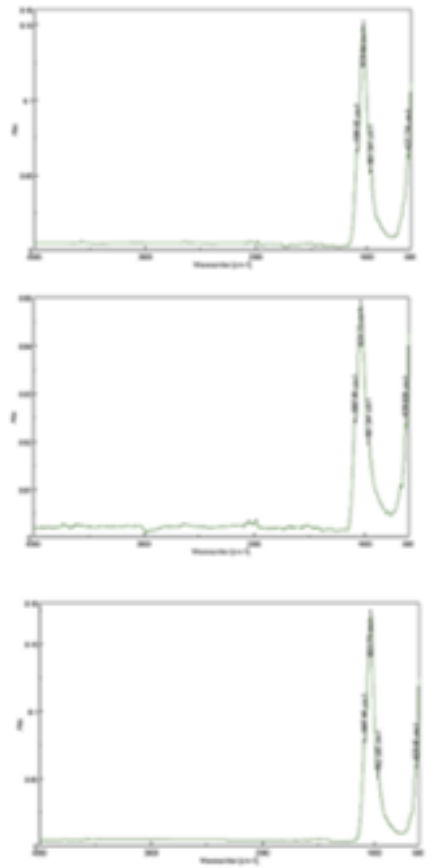

(c)

Fig. 2. FTIR spectra of experimental $\mathrm{HA}$ based composites obtained at different sintering temperatures $\left(\mathrm{a}-1000{ }^{\circ} \mathrm{C}, \mathrm{b}-1100{ }^{\circ} \mathrm{C}, \mathrm{c}-1200{ }^{\circ} \mathrm{C}\right.$ )

A

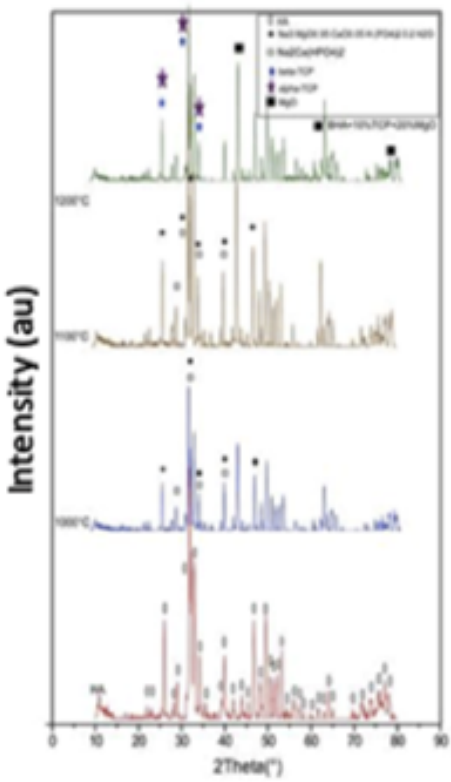

B

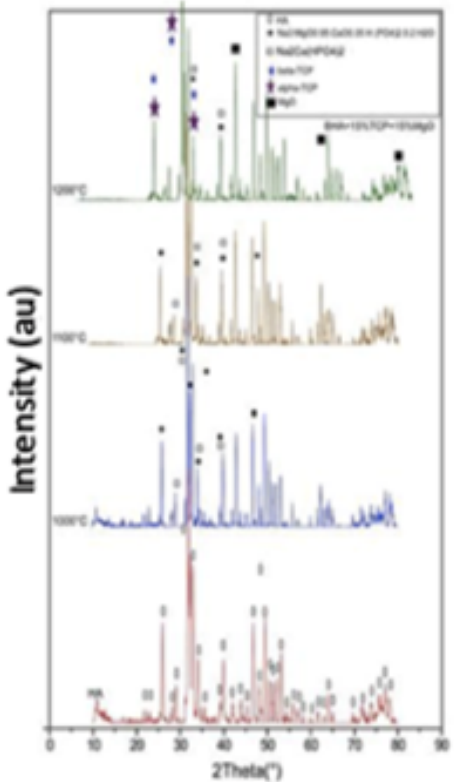

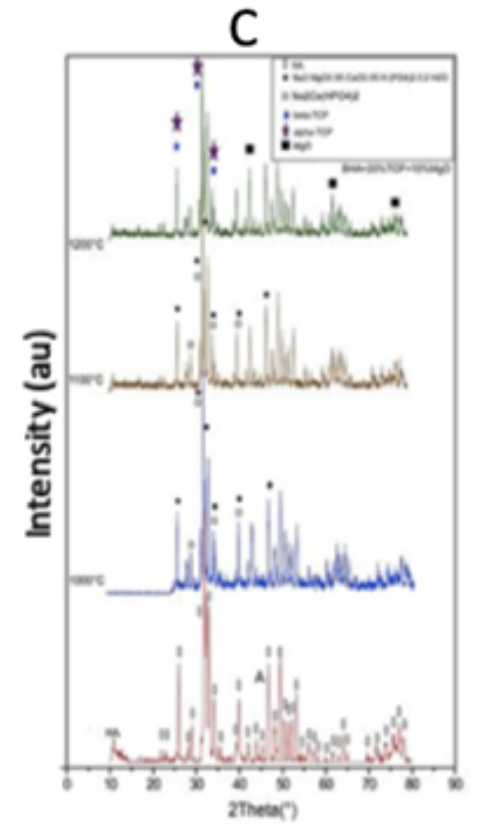

Fig. 3. The diffraction spectra of experimental composite samples and good sintering at high temperatures is observed. The surface structure observed at SEM analysis is shown in Figure 4.

\section{Vickers microhardness and compressive strength}

Hardness is a characteristic of the material, not a fundamental physical property. This is defined as resistance to penetration and is determined by measurement of the depth of penetration. Simply put, when a force and a penetrator are used, the smaller dentleft behind the process reveals a more resistant material. The hardness value is obtained by measuring the depth or the surface left after penetration by means of 12 different test methods. The Vickers hardness test method is a microstructure test method used mainly for small parts or thin sections and is based on an optical measurement system. In the experimental study the microhardness measurement was made using VHMOT, Leica. The Vickers microhardness was determined for all sintered composites at 1000, 1100 and $1200{ }^{\circ} \mathrm{C}$. For each type of experimental material, three determinations were made. The variation of the obtained microhardness is shown in the figure 5 .

The compressive strength of the composite materials obtained was compressed using a load applied gradually while recording the maximum value of the compressive load supported by the material before fracturing. The best values of compression resistance using bovine hydroxyapatite were obtained for specimens containing $20 \%$ TCP and $10 \% \mathrm{MgO}$ sintered at $1100{ }^{\circ} \mathrm{C}$ as it can be observed from figure 6. 
A

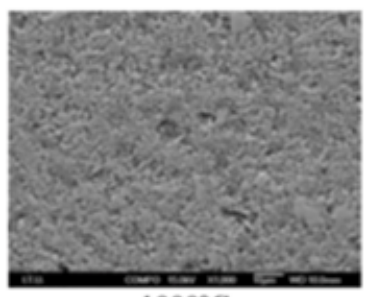

$1000^{\circ} \mathrm{C}$

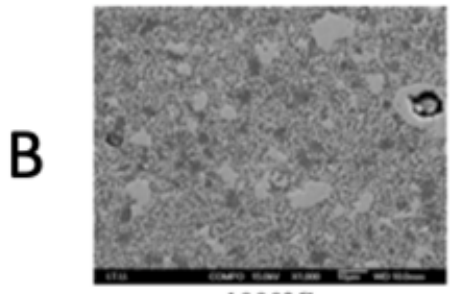

$1000^{\circ} \mathrm{C}$

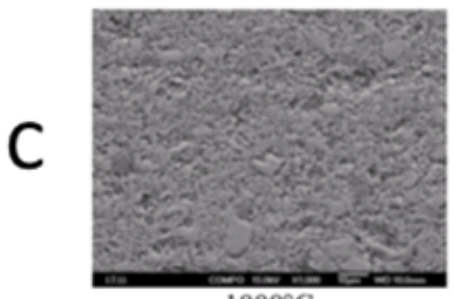

$1000^{\circ} \mathrm{C}$

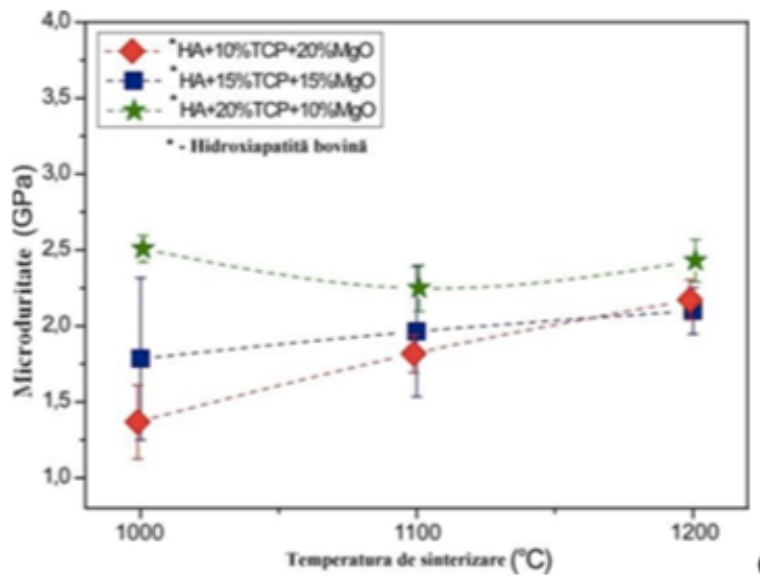

Fig. 5. Variation of Vickers microhardness

$1100^{\circ} \mathrm{C}$

$1100^{\circ} \mathrm{C}$

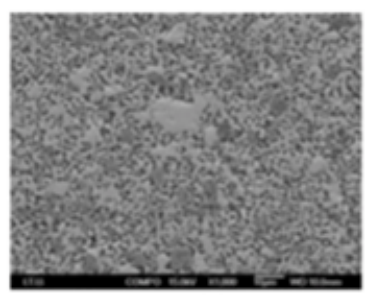

$1200^{\circ} \mathrm{C}$
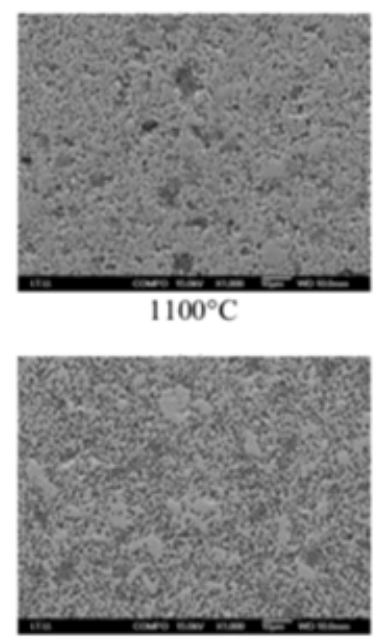

(a)

\section{Conclusions}

Our experimental study on developing new bone substitutes as ceramic-ceramic composite biomaterials revealed different properties depending on the sample composition as well as sintering temperatures. According to our experimental data presented in this paper it is noted that using HA from bovine source, the experimental composites show ed a higher degree of homogeneity due to the increase of the sintering temperature. Numerous previous studies have confirmed that magnesium oxide has beneficial effects on the human body as it improves the early stages of mineralization and contributes to a close relationship with living tissue. From a biological point of view, magnesium is a matter of interest because of its physiological role in positively influencing bone resistance. The use of magnesium oxide as the reinforcing element, the major novelty element of new composite materials, has led to the obtaining of mechanical properties superior to biocomposites used today as bone substitutes (hydroxyapatite-tricalcium phosphate), respectively, of microdurity and compressive strength. In conclusion, itcan be said thatcertain biocomposites having the bovine source HA matrices, reinforced with a certain percentage of

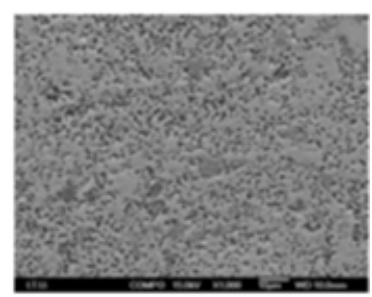

$1200^{\circ} \mathrm{C}$

\section{References}

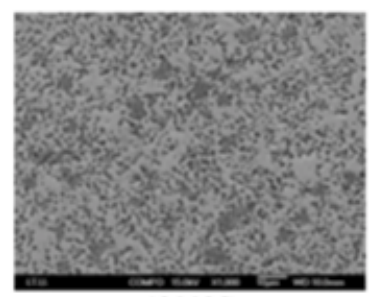

Fig. 4. SEM images of experimental hydroxyapatite based composites

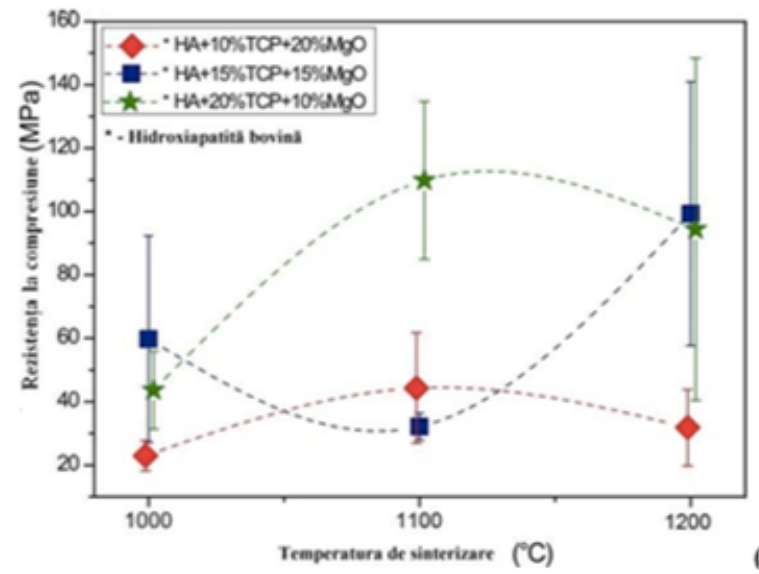

(a)

Fig. 6. Compressive strenght of HA based composite samples depending on the sintering temperature

tricalcium $\beta$ - phosphate and magnesium oxide, can be used as structural substitutes from the structural point of view and mechanical properties.

1.MICULESCU, F.; BOJ IN, D.; CIOCAN, L. T.; et al., Experimental researches on biomaterial-tissue interface interactions, JOURNAL OF OPTOELECTRONICS AND ADVANCED MATERIALS Volume: 9 Issue: 11 Pages: 3303-3306 Published: NOV 2007

2.BITA, ANA-IULIA; STAN, G. E.; NICULESCU, M.; et al., Adhesion evaluation of different bioceramic coatings on Mg-Ca alloys for biomedical applications, JOURNAL OF ADHESION SCIENCE AND TECHNOLOGY Volume: 30 Issue: 18 Pages: 1968-1983 Published:2016 3.ANTONIAC, IULIAN; NEGRUSOIU, MIHAI; MARDARE, MIHAI; et al., Adverse local tissue reaction after 2 revision hip replacements for ceramic liner fracture A case report, MEDICINE Volume: 96 Issue: 19 Article Number: e6687 Published: MAY 2017

4.BENEA, HOREA; TOMOAIA, GHEORGHE; SORITAU, OLGA; et al., A Review on the Reconstruction of Articular Cartilage Using Collagen Scaffolds, ROMANIAN BIOTECHNOLOGICAL LETTERS Volume: 21 Issue: 4 Pages: 11720-11728 Published: JUL-AUG 2016 
5.MARINESCU, R.; ANTONIAC, I.; LAPTOIU, D.; et al., Complications Related to Biocomposite Screw Fixation in ACL Reconstruction Based on Clinical Experience and Retrieval Analysis, Mat. Plast., 52, no. 3, 2015, p.340-344

6.BOTEZ, P.; SIRBU, P.; SIMION, L.; et al., Application of a biphasic macroporous synthetic bone substitutes $\operatorname{CERAFORM}(A(R))$ : clinical and histological results, EUROPEAN JOURNAL OF ORTHOPAEDIC SURGERY AND TRAUMATOLOGY Volume: 19 Issue: 6 Pages: 387- 395 Published: AUG 2009

7.RIVIS, M.; PRICOP, M.; TALPOS, S.; et al., Influence of the Bone Cements Processing on the Mechanical Properties in Cranioplasty, Rev. Chim. (Bucharest), 69, no. 4, 2018, p. 990-993

8.ANTONIAC, IULIAN; SINESCU, COSMIN; ANTONIAC, AURORA, Adhesion aspects in biomaterials and medical devices, JOURNAL OF ADHESION SCIENCE AND TECHNOLOGY Volume: 30 Issue: 16 Special Issue: SI Pages: 1711-1715 Published: AUG 172016

9.GRECU, D.; ANTONIAC, I.; TRANTE, O.; et al., Failure Analysis of Retrieved Polyethylene Insert in Total Knee Replacement, Mat. Plast., 53, no. 4, 2016, p. 776-780

10.RAU, JULIETTA V.; ANTONIAC, IULIAN; CAMA, GIUSEPPE; et al., Bioactive Materials for Bone Tissue Engineering, BIOMED RESEARCH INTERNATIONAL Article Number: 3741428 Published: 2016

11.STANCU, IZABELA-CRISTINA; DRAGUSIN, DIANA MARIA; VASILE, EUGENIU; etal., Porous calcium alginate-gelatin interpenetrated matrix and its biomineralization potential, JOURNAL OF MATERIALS SCIENCEMATERIALS IN MEDICINE Volume: 22 Issue: 3 Pages: 451-460 Published: MAR 2011

12.RUSEN, EDINA; MOCANU, ALEXANDRA; MARCULESCU, BOGDAN; et al., Obtaining complex structures starting from monodisperse poly(styrene-co-2-hydroxyethylmethacrylate) spheres, COLLOIDS AND SURFACES A-PHYSICOCHEMICAL AND ENGINEERING ASPECTS Volume: 375 Issue: 1-3 Pages: 35-41 Published: FEB 52011
13.PETREUS, TUDOR; STOICA, BOGDAN ALEXANDRU; PETREUS, OANA; et al., Preparation and cytocompatibility evaluation for hydrosoluble phosphorous acid-derivatized cellulose as tissue engineering scaffold material, JOURNAL OF MATERIALS SCIENCEMATERIALS IN MEDICINE Volume: 25 Issue: 4 Pages: 11151127 Published: APR 2014

14.NICULESCU, M.; ANTONIAC, A.; VASILE, E.; et al., Evaluation of Biodegradability of Surgical Synthetic Absorbable Suture Materials: An In Vitro Study, Mat. Plast., 53, no. 4, 2016, p: 642-645

15.EARAR, K.; GRADINARU, S.; PARIZA, G.; et al., Effect of the Sterilization Procedures of Different Surgical Meshes for Abdominal Surgery, Rev. Chim. (Bucharest), 68, no. 8, 2017, p. 1868-1873

16.MAVRODIN, C. I.; PARIZA, G.; ION, D.; et al., Abdominal Compartment Syndrome - A Major Complication of Large Incisional Hernia Surgery, CHIRURGIA Volume: 108 Issue: 3 Pages: 414-417 Published: MAY-JUN 2013

17.PARIZA, G.; MAVRODIN, C.I.; ANTONIAC, I., Dependency Between the Porosity and Polymeric Structure of Biomaterials Used in Hernia Surgery and Chronic Mesh - infection, Mat. Plast., 52, no. 4, 2015, p: 484-486

18.AHN JH, WANG JH, LEE YS, et al. Anterior cruciate ligament reconstruction using remnant preservation and a femoral tensioning technique: clinical and magnetic resonance imaging results. Arthroscopy. 2011;27:1079-89.

$\overline{\text { Manuscript received: } 14.07 .2019}$ 